\title{
O profissional de saúde e o segredo profissional: perspectivas da Enfermagem
}

\author{
Thiago Luis de Andrade Barbosa*, Ludmila Mourão Xavier Gomes**, Orlene Veloso Dias, M.Sc.***, \\ Luís Paulo Souza e Souza ${ }^{* * * *}$, Simone de Melo Costa ${ }^{* * * * *}$, Antônio Lincoln de Freitas Rocha******
}

\begin{abstract}
*Enfermeiro, Doutorando em Ciências da Saúde pela Universidade Estadual de Montes Claros (Unimontes), Montes Claros/ $M G$, ${ }^{*}$ Enfermeira, Professora Doutoranda do Departamento de Enfermagem das Faculdades Santo Agostinho, Montes Claros/MG, ${ }^{* * *}$ Enfermeira, Professora Mestre do Departamento de Enfermagem da Unimontes, ${ }^{* * * * E n f e r m e i r o, ~ M e s t r a n d o ~}$ pela Universidade Federal de Minas Gerais, Belo Horizonte/MG, *****Dentista, Professora Doutora do Departamento de Odontologia da Unimontes, ******Acadêmico do Curso de Graduação em Medicina da Unimontes
\end{abstract}

\section{Resumo}

O estudo teve por objetivo abordar questóes pertinentes à temática do segredo profissional, destacando a importância desse tema para os profissionais de enfermagem. Foi realizada uma pesquisa bibliográfica, com base em artigos eletrônicos e livros publicados nos últimos 14 anos. A privacidade das informaçôes dos usuários dos serviços de saúde é prevista em lei e discutida também pelos conselhos de ética das profissóes, já que envolve a vida privada e a intimidade das pessoas. Dessa forma, pode-se perceber que esse tema é de grande relevância para a formação profissional, principalmente da enfermagem, pois requer do profissional uma reflexão adequada e, para isso, ele deve estar devidamente preparado para assumir uma conduta nos casos em que está em jogo a privacidade do usuário.

Palavras-chave: comunicação sigilosa, Enfermagem, ética.

\section{Abstract}

The healthcare professional and professional confidentiality: Nursing perspectives

This study aimed at addressing pertinent questions to the issue of confidentiality, emphasizing the importance of this theme for the nursing profession. We performed a literature review, based on electronic items and books published in the last 14 years. The information privacy of users of health services is guaranteed by law and also discussed by the professional ethics committee, as it involves private life and individual privacy. Thus, one can see that this topic is of great importance to vocational training, mainly of nursing, as it requires an adequate professional reflection and, therefore, he should be ready to assume responsibilities when user privacy is at stake.

Key-words: confidentiality, Nursing, ethics. 


\section{Resumen}

\section{El profesional de la salud y el secreto profesional: perspectivas de Enfermería}

Este estudio tuvo como objetivo abordar cuestiones pertinentes a la temática confidencialidad profesional, destacando la importancia de este tema para los profesionales de enfermería. Se llevó a cabo una búsqueda bibliográfica con base en artículos electrónicos y libros publicados en los últimos 14 años. La privacidad de la información de los usuarios de los servicios de salud está prevista por ley y examinada también por los consejos de ética profesional, ya que envuelve la privacidad e intimidad de las personas. De esta forma, se puede percibir que este tema es de gran importancia para la formación profesional, principalmente de enfermería, pues requiere del profesional una reflexión apropiada y, para ello, debe estar debidamente preparado para adoptar una conducta adecuada en casos de que la privacidad está en juego.

Palabras-clave: confidencialidad, Enfermería, ética.

\section{Introdução}

O segredo profissional e a confidencialidade de informaçóes dos usuários do serviço de saúde são imprescindíveis para consecução de uma assistência adequada. A formação dos profissionais de saúde deve estar ancorada em princípios éticos e morais de maneira que possa garantir o resguardo de informaçôes e dados do cliente. Diante disso, é fundamental que os trabalhadores conheçam toda a legislação correspondente à sua área profissional [1] .

É de extrema importância manter segredo das informaçóes do cliente, nas situaçóes adequadas, e preservar sua privacidade, o que remete a uma questão ética, moral e de humanização. Deve-se considerar que, em se tratando de privacidade, não importa a idade, cor, sexo ou orientação sexual do cliente. É um aspecto que deve contemplar desde recém-nascidos até pessoas idosas [2].

Entretanto, é valido dizer que o código de ética de determinada categoria profissional dificilmente contempla todas as situaçôes que possam acontecer, todavia procura fornecer orientaçóes aos profissionais acerca dos comportamentos esperados deles nas relaçóes com o cliente e com os colegas e outros profissionais em relação às circunstâncias nas quais se devem manter sigilo [3].

Nesse sentido, o segredo profissional e a confidencialidade dada sua relevância constituem ainda elementos essenciais de instrumentos como o Código Penal e o Código deontológico dos profissionais de saúde, dentre eles o da enfermagem $[4,5]$. Nesse sentido, existe uma legislação específica para a temática, estabelecendo direitos e deveres dos profissionais em diversas situaçôes, nos mais diversos contextos. Além disso, a sociedade atual dispóe de um conjunto muito vasto de informaçóes a respeito dos indivíduos e das instituiçóes para viabilizar o atendimento aos usuários, planejar a alocação de recursos, planejar as gestôes de serviços de saúde. Diante de tantas informaçóes, obtidas das mais diversas formas, ampliam-se as possibilidades e riscos de haver um uso indevido e de quebra de privacidade de indivíduos e mesmo de instituiçôes [6].

O direcionamento das abordagens na área da enfermagem é de grande relevância, pois seus profissionais, especialmente os enfermeiros, lidam, na maior parte do tempo, com questóes envolvendo a confidencialidade diretamente, o que se revela como uma boa oportunidade para o enfermeiro demonstrar sua proficiência e propriedade enquanto profissional de saúde. Ainda mais tendo em vista que os profissionais de enfermagem estão em constante contato com o usuário, sendo responsáveis por atender a maioria das suas necessidades e, portanto, constituindo parte indispensável para uma assistência de qualidade. Diante do exposto, o presente estudo trata-se de uma reflexão acerca do segredo profissional e a confidencialidade na perspectiva da enfermagem.

\section{Material e métodos}

Trata-se de uma revisão bibliográfica realizada a partir das publicaçóes disponíveis nas principais bases de dados: Scielo e Lilacs. As buscas foram realizadas utilizando-se as palavras-chave "Segredo Profissional", "Sigilo Profissional" "Comunicação Sigilosa", "Privacidade das informaçōes" e "Confidencialidade das Informaçóes" de publicações 
referentes aos últimos 14 anos. Após a pesquisa com os descritores, os artigos foram identificados através do ano, autores, resumos e área temática, selecionando àqueles que se enquadravam ao objetivo deste estudo.

A discussão deontolágica foi conduzida com base no Código de Ética dos Profissionais de Enfermagem (Resolução COFEN 311/2007) e o Código Penal $[4,5]$. Foi ainda utilizado como referenciais livros-textos contemporâneos de especialistas da área de educação sobre tais temas. Posteriormente à pesquisa bibliográfica, realizou-se a seleção e leitura dos artigos e livros-textos, de forma reflexiva, buscando discutir a problemática que envolve o segredo profissional.

\section{Resultados e discussão}

\section{Segredo profissional e sigilo profissional na En- fermagem}

No âmbito da saúde bem como na Enfermagem, os termos segredo profissional, sigilo de informaçóes e confidencialidade são muito comuns, pois estão diretamente relacionados à atuação dos diversos profissionais da área.

O sigilo profissional é parte integrante em todas as profissóes na área da saúde; todavia, o segredo profissional envolve além desses profissionais aqueles de outras formaçóes que trabalham em instituiçóes de saúde. Convém ressaltar que todas as informaçóes fornecidas pelos usuários atendidos em hospitais, unidades de saúde inclusive consultórios particulares, bem como resultados de exames ou qualquer documento resultante de procedimentos com finalidade diagnóstica ou terapêutica, são de propriedade dos usuários [7].

A garantia do sigilo é aplicável às informações reveladas espontaneamente pelo cliente, assim como àquelas que forem descobertas no decorrer do atendimento ou tratamento. Além disso, este tema abrange diversas situaçóes conflitantes, que podem trazer dúvidas ao enfermeiro, entre revelar e não revelar o segredo que lhe foi confiado durante o exercício de sua profissão [8]. Entretanto, muitas vezes os termos sigilo e segredo sáo utilizados de uma forma inadequada [9]. A palavra "segredo" pode significar simplesmente ocultação ou preservação de informaçóes, as quais dizem respeito à intimidade da pessoa e, portanto, devem ser mantidos e preservados de forma idônea. A denominaçáo "sigilo" tem sido cada vez menos utilizada e em seu uso nos diferentes idiomas está relacionada a aspectos de ocultação, sendo menos utilizada no sentido de preservação [10].

Autores propóem duas categorias principais nas quais os tipos de segredo se dividem: o segredo natural e o profissional. O segredo natural é aquele que se vem a ter conhecimento fora do exercício profissional, enquanto o segredo profissional é aquele que se vem, a saber, exercendo-se uma atividade profissional [11].

Diante disso, o profissional de enfermagem, em seus contatos diários com pacientes, familiares e funcionários, depara-se com informaçóes que náo pode revelar e outras que pode ou mesmo deve revelar. Mas como saber o que revelar ou náo? E a quem? São questôes levantadas principalmente considerando-se que esse assunto diz respeito a aspectos humanos, jurídicos e deontológicos. $\mathrm{O}$ segredo fundamenta-se na confiança, na confidência e na justiça e, ao se guardar ou revelar um segredo indevidamente, respeita-se ou desrespeita-se a justiça, tendo em vista que o segredo pertence ao usuário do serviço [12].

O Código de Ética dos Profissionais de Enfermagem [4] traz em seu artigo 81, o direito do profissional de não revelar as informaçóes confidenciais de que tenha conhecimento em virtude do seu exercício profissional a pessoas ou entidades que náo estejam obrigadas ao sigilo. E, enquanto responsabilidades e deveres, o artigo 82 determina que se deve manter segredo sobre fato sigiloso de que tenha conhecimento em razáo de sua atividade profissional, exceto nos casos previstos em lei, ordem judicial, ou com consentimento escrito da pessoa envolvida ou de seu representante legal. Além disso, nos parágrafos desse mesmo artigo pode-se constatar:

\section{Segredo profissional e confidencialidade}

Para que o usuário confie no profissional, a confidencialidade das informaçóes é fundamental. É importante que o sigilo das informaçóes seja mantido para que o usuário frequente o serviço de saúde. Nesse sentido, compete aos profissionais de enfermagem estabelecer condiçóes para que o usuário possa decidir sobre quais informaçóes quer manter em segredo e aquelas que deseja comunicar aos familiares, amigos ou aos profissionais de saúde [12]. Contudo, a maneira como são enfrentados os problemas éticos sob a ótica dos profissionais de 
enfermagem é algo que merece ser bem trabalhado desde a formação haja vista os grandes desafios vivenciados no dia a dia em situações que precisam ser discutidas e problematizadas [13].

Entre outros problemas na saúde, existem as muitas críticas na formação de seus profissionais de saúde, sendo que algumas delas relacionadas às atitudes éticas ou às relações profissionais. Atualmente, já se constata um esgotamento do modelo tradicional de formação e este não está sendo adequado às demandas atuais [14]. Entretanto, a garantia da privacidade e da confidencialidade confere aos profissionais de saúde credibilidade frente ao cliente [15].

Na perspectiva de Francisconi e Goldim [10], a manutenção do segredo está vinculada tanto à questão da privacidade quanto da confidencialidade. Em se tratando de privacidade, o profissional tem o dever de resguardar as informaçóes que teve contato e preservar a pessoa do cliente, o que se traduz até mesmo num dever institucional. Já a confidencialidade pressupóe que o usuário repasse as informaçóes diretamente ao profissional, ficando esse responsável pela preservação das mesmas. A palavra "confidencialidade" tem origem no termo "confiança", que é fundamental para um bom relacionamento terapêutico. O cliente confia que o profissional de saúde preservará tudo o que lhe for dito, tanto que, muitas vezes, até mesmo as pessoas mais próximas dele não têm conhecimento dessas informaçōes.

Outro ponto a ser destacado no segredo profissional diz respeito à garantia de proteçáo ao cliente como uma condiçáa que, embora assegurada desde o início na relação profissional, atua no a posteriori da revelação. No código de deontologia, essa proteção se traduz pela "não divulgação" das informações. Em outras palavras, o paciente revela coisas secretas e o terapeuta, por sua vez, se compromete a trabalhar no segredo, formando uma relação do tipo causa e efeito. No entanto, pode-se fazer outra leitura na qual se inverte tal relaçáo, ou seja, o segredo torna-se não mais uma garantia que protege o paciente, mas uma técnica particular com vista à construção de um processo específico [16].

A ética e o dever legal são instâncias diferentes e a relação de confiança construída pela confidencialidade é um pilar das relaçóes entre profissionais da saúde e pacientes. A dimensão humana é moldada no âmbito das relaçóes. Quando se discute bioética, está-se falando em relações humanas [7].
O direito à privacidade e à confidencialidade dos dados náo é considerado como direito absoluto tanto ética quanto legalmente. A quebra do sigilo pode acontecer devido ao próprio consentimento do cliente ou seu representante legal, por dever legal, ou mesmo pela existência de uma "justa causa". Além disso, ocultar fato de que se tem ciência, mas que deveria ser revelado, pode igualmente infringir a justiça e o direito comunitário. Por exemplo, quando um cliente revela a um profissional de enfermagem que possui doença contagiosa de notificaçáo compulsória, tal segredo não deve ser mantido, pois coloca em risco a saúde da comunidade. Diante de situações como essa, evidencia-se a importância de saber avaliar quando revelar ou guardar um segredo [17].

\section{O segredo profissional e privacidade}

A privacidade é um princípio derivado da autonomia, englobando a vida privada, a imagem e a intimidade dos indivíduos. Para que seja garantida a privacidade desses indivíduos é necessário o respeito à confidencialidade das informaçóes em questão. É dever dos profissionais e gestores de serviços de saúde assegurarem condiçóes para que o paciente, enquanto sujeito autônomo e, portanto, dotado de livre escolha, possa determinar que informaçóes deseja manter sob seu exclusivo controle e quais pretende compartilhar com terceiros, de modo que decida quando, onde e em que condiçóes quer que tais informações sejam reveladas [17].

Em consonância, autores [10] expóem que qualquer informação fornecida por pacientes na ocasião de seu atendimento no hospital, posto de saúde ou consultórios privados, como também as provenientes de resultados de exames e procedimentos realizados com finalidade diagnóstica ou terapêutica são de sua exclusiva propriedade. Mas isso nem sempre foi interpretado assim. Houve, durante muito tempo, a percepçáo de que tais informaçóes pertenciam ao médico ou à instituição de saúde. Daí as denominaçóes "prontuário médico" e "arquivo médico”, até hoje comumente encontradas. $\mathrm{Na}$ verdade, os trabalhadores da saúde e as instituiçóes são apenas depositários dessas informaçóes, o que traduz a necessidade de atualizar a forma como se trata as informaçóes do usuário. $\mathrm{O}$ que justifica o acesso às informaçóes contidas no prontuário é a necessidade profissional, e qualquer um que faça uso das mesmas não tem o direito de usá-las livre- 
mente, o que traduz um direito ao acesso somente às informaçóes que contribuam efetivamente para o atendimento do usuário.

O dever ético e legal dos profissionais de saúde tem origem justamente na garantia da privacidade e confidencialidade das informaçóes dos pacientes, mantendo, assim, o sigilo das informaçôes. Esse segredo profissional no trabalho de assistência à saúde é evidenciado no pensamento hipocrático, que afirmava: "As coisas que eu verei ou ouvirei dizer no exercício da minha arte, ou fora de minhas funçóes, no comércio dos homens, e que não deverão ser divulgadas, eu calarei, percebendo-as como segredos invioláveis" [17].

Dessa forma, percebe-se que a privacidade e o sigilo profissional são instrumentos multiprofissionais e abrangem não apenas enfermeiros e médicos, mas também outras categorias profissionais. Autores [18] demonstram em seu estudo que o frequente contato dos usuários com o Agente Comunitário de Saúde (ACS) leva à constatação de que os primeiros costumam revelar aspectos de suas condiçôes de saúde para o agente até mesmo antes de comunicarem aos outros componentes da equipe de saúde, o que pode levar a um impasse ético para os ACS, à medida que tal situaçáo evidencia um problema pertinente ao posicionamento do próprio agente comunitário: como preservar as informaçóes do ACS enquanto morador de uma determinada comunidade e enquanto vizinho?

O caráter sigiloso das informaçóes deve ser observado tanto em comunicaçóes orais quanto escritas com os profissionais, com a imprensa ou mesmo autoridades; o sigilo aplica-se, dessa forma, em cartas, divulgaçóes à imprensa, boletins médicos, discussóes de casos, conferências e congressos com exibição de imagens, fotografias, radiografias, nas perícias e auditorias [17].

A revelação de um segredo transforma uma relação interpessoal em uma relação assimétrica, já que deixa a parte que revelou o segredo em posiçáo vulnerável relativamente à relação interpessoal [7]. Trazendo essa questão do segredo profissional para um contexto mais específico para a enfermagem, no espaço hospitalar, os enfermeiros, mais do que qualquer outro profissional da área da saúde, possuem muitas oportunidades para colocar em prática o respeito pelos direitos dos usuários. Enquanto líderes de uma equipe, os enfermeiros constituem-se em uma fonte de contato pessoal e íntimo com os usuários, sendo responsáveis por implementar os cuidados de cada cliente, de forma individual, o que viabiliza as ações de orientação e prestação de informaçóes precisas a respeito dos procedimentos que os integrantes da equipe realizarão com ele e para ele [19].

\section{Questóes legais envolvendo o segredo profissional}

O segredo profissional é passível de ser revelado de forma direta ou indireta. Diz-se que a revelaçáo é direta quando sáo publicados o conteúdo e o nome da pessoa a quem pertence o segredo. A revelação é indireta se forem oferecidos indicativos para o conhecimento do segredo e do seu dono. Embora a revelação seja direta ou indireta, a (in)justiça é praticada da mesma forma e as responsabilidades jurídica e deontológica se fazem presentes nas situaçóes. Existem situaçóes nas quais o segredo pode ser revelado e outras em que deve ser manifestado a quem tem o direito. A importância desse aspecto reside no fato de que o profissional pode ser processado ou ferir a deontologia revelando ou guardando um segredo [11].

Estabelece-se, também, como dever do enfermeiro, no artigo 83, orientar sua equipe sobre o sigilo profissional. O Código de Ética dos Profissionais de Enfermagem [4] proíbe franquear o acesso a informaçôes e documentos a pessoas que não estão diretamente vinculadas à prestação da assistência, excetuando-se os casos previstos em lei ou por ordem judicial (Art. 84) e divulgar ou mesmo fazer referência a casos, situaçóes ou fatos de forma que os envolvidos possam ser reconhecidos (Art 85).

Já o Código Penal [5], em seu Artigo 153, define que é crime divulgar alguém, sem justa causa, conteúdo de documento particular ou de correspondência confidencial, de que é destinatário ou detentor, e cuja divulgação possa produzir dano a outrem. O Artigo 154 presume que é crime revelar a alguém, sem justa causa, segredo, de que tem ciência em razão de função, ministério, ofício ou profissão, e cuja revelação possa produzir dano a outrem. Parágrafo único - Somente se procede mediante representação.

Pode-se revelar o segredo quando o dono permite, quando o bem de terceiros o exige, quando o bem do depositário o exige ou quando o bem comum o exige. Entre as situaçóes nas quais o segredo deve ser revelado, têm-se: ao se tratar de uma declaraçáo de nascimento; a fim de se evitar um casamento, nos casos em que patologias possam pôr 
em risco um dos cônjuges ou a prole; na declaração de doenças de notificação compulsória; em se tratando de fato delituoso previsto em lei; em caso de sevícias de menores; quando se tem conhecimento de abortadores profissionais, nas perícias médico-legais e nos registros de livros hospitalares. Quando se revela, indevidamente, um segredo profissional, desrespeita-se a confiança depositada e pode-se ocasionar grave prejuízo ao bom nome, à honra ou à profissão [11].

Nas situaçóes em que ocorre a quebra de privacidade ou confidencialidade, deve ficar claro o dever de lealdade do profissional para com o cliente, sendo de extrema importância que tal compromisso seja preservado, ainda que o cliente esteja inconsciente ou, até mesmo, após sua morte. Contudo, o sigilo pode ser quebrado, em situaçóes em que haja justa causa e com amparo na legislação. Assim, em situaçóes como testemunhar em corte judicial, situaçóes compatíveis com a gravidade, notificação à autoridade competente a existência de doenças ou situações de informação compulsória, maus tratos em crianças ou adolescentes, abuso de cônjuge ou idoso e ferimento por arma de fogo ou outro tipo de arma, quando se suspeita que a lesão tenha ocorrido em função de ato criminoso [10].

Quando o profissional é chamado para testemunhar em Corte Judicial, deve declarar-se impedido de revelar qualquer informaçáo, pois está eticamente comprometido com o resguardo das informaçóes. No entanto, existem situações nas quais um juiz pode assumir a responsabilidade e requerer a revelação das informaçôes, ainda que isso seja contra o que estabelece o código de ética profissional, desde que tal fato fique claramente registrado nos autos do processo, o que caracteriza uma exceção e não uma quebra à confidencialidade. Esse caminho pode corresponder aos aspectos legais do ato de revelar informaçóes caracterizadas como confidenciais, mas não contempla plenamente os aspectos morais e éticos envolvidos [10].

Por outro lado, ao analisar a questão de segredo profissional, constata-se a existência de aspectos jurídicos e deontológicos [11]. Comumente, dá-se mais importância à infração legal, deixando de lado as questóes deontológicas, o que torna necessária a mudança de postura diante desse quadro, pois ao violar um segredo, desobedecem-se leis, mas também se violam aspectos fundamentais do ser humano: o respeito, a justiça, a confiança e a confidência.

\section{Conclusão}

Diante do exposto, fica claro a grande importância da temática do segredo profissional no tocante à Enfermagem, tanto no âmbito acadêmico (formação) quanto no profissional. É necessária a existência de discussóes acerca do assunto, para que os trabalhadores da saúde conheçam seus direitos e deveres, assumindo uma postura adequada diante das mais diversas ocasiōes. Tal conhecimento facilita o entendimento dos problemas, os quais muitas vezes podem instigar no profissional de saúde sérias dúvidas, tornando sua conduta inadequada ou insegura.

Outro aspecto que merece destaque diz respeito ao fato de tratar o ser humano não como mero objeto, mas como alguém dotado de história, experiências e vivências. Nesse sentido, é imprescindível avaliar todas as questóes que envolvem o segredo e sigilo profissional. Há obrigação dos profissionais e serviços de saúde em adotar medidas para minimizar as violaçóes dos princípios éticos e garantir o caráter sigiloso das informaçôes. Essa obrigação é invariável, ou seja, aplica-se tanto a serviços públicos como privados, em âmbito ambulatorial ou hospitalar, em convênios ou serviços gratuitos.

\section{Referências}

1. Souza ML, Sartor VVB, Prado ML. Subsídios para uma ética da responsabilidade em enfermagem. Texto Contexto Enferm 2005;14(1):75-81.

2. Ferreira HM, Ramos LH. Diretrizes curriculares para o ensino da ética na graduação em enfermagem. Acta Paul Enferm 2006;19(3):328-31.

3. Freitas GF, Oguisso T, Fernandes MFP. Fundamentos éticos e morais na prática de enfermagem. Enfermagem em Foco 2010;1(3):104-8.

4. Conselho Federal de Enfermagem. Código de Ética dos Profissionais de Enfermagem. Rio de Janeiro: Cofen; 2007.

5. Brasil. Decreto-Lei no. 2.848, de 07 de dezembro de 1940 (Código Penal).

6. Rego S, Gomes AP, Siqueira-Batista R. Bioética e Humanização como Temas Transversais na Educação Médica. Rev Bras Educ Med 2008;32(4):482-91.

7. Gobbetti GJ. A função da confidencialidade: bioética e incesto [tese]. São Paulo: Universidade de São Paulo, Programa de Pós-Graduação em Ciências Médicas; 2006.

8. Mendonça AC, Villar HCCE, Tsuji SR. O conhecimento dos estudantes da Faculdade de Medicina de Marília (Famema) sobre responsabilidade profissional e segredo médico. Rev Bras Educ Médica 2009;33(2):221-9.

9. Carneiro LA, Porto CC, Duarte SBR, Chaveiro N, Barbosa MA. O ensino da ética nos cursos de graduação da área de saúde. Rev Bras Educ Med 2010;34(3):412-21. 
10. Francisconi CF, Goldim JR. Aspectos Bioéticos da Confidencialidade e Privacidade. In: Costa, SIF, Oselka G, Garrafa V. Iniciação à Bioética. Brasília: Conselho Federal de Medicina, 1998. 319p.

11. Gelain I. Deontologia e Enfermagem. 3ed. São Paulo: EPU; 1998. 141p.

12. Abdalla FTM, Nichiata LYI. A abertura da privacidade e o sigilo das informaçóes sobre o HIV/Aids das mulheres atendidas pelo Programa Saúde da Família no município de São Paulo, Brasil. Saúde Soc 2008;17(2):140-52.

13. Bordignon SS, Lunardi VL, Dalmolin GL, Tomaschewski JG, Lunardi Filho WDL, Barlem ELD, et al. Questóes éticas do cotidiano profissional e a formação do enfermeiro. Rev Enferm UERJ 2011;19(1):94-9.

14. Ferreira RC, Silva RF, Zanolli MB, Varga CRR. Relaçóes éticas na Atenção Básica em Saúde: a vivência dos estudantes de medicina. Ciênc Saúde Coletiva 2009;14(1):1533-40.
15. Ferreira FC, Nichiata LYI. Mulheres vivendo com AIDS e os profissionais do Programa Saúde da Família: revelando o diagnóstico. Rev Esc Enferm USP 2008;42(3):483-9.

16. Zoboli, ELCP, Fortes PAC. Bioética e atenção básica: um perfil dos problemas éticos vividos por enfermeiros e médicos do Programa Saúde da Família, São Paulo, Brasil. Cad Saúde Pública 2004;20(6):1690-9.

17. Fortes PAC, Zoboli ELCP. Bioética e Saúde Pública: entre o individual e o coletivo. São Paulo: Loyola; 2003. p.11-24.

18. Fortes PAC, Spinetti SR. O agente comunitário de saúde e a privacidade das informaçóes dos usuários. Cad Saúde Pública 2004;20(5):1328-33.

19. Trevizan MA, Mendes IAC, Lourenço MR, Shinyasshiki GT. Aspectos éticos na ação gerencial do enfermeiro. Rev Latinoam Enferm 2002;10(1):85-9. 